\title{
Curbing Bullying
}

\author{
J. B. Moores \\ Rockaway Place, Lexington, KY, USA \\ Email: Br00ke127@aol.com
}

How to cite this paper: Moores, J. B. (2017). Curbing Bullying. Psychology, 8, 2011-2016.

https://doi.org/10.4236/psych.2017.812128

Received: June 20, 2017

Accepted: October 17, 2017

Published: October 20, 2017

Copyright $\odot 2017$ by author and Scientific Research Publishing Inc. This work is licensed under the Creative Commons Attribution International License (CC BY 4.0).

http://creativecommons.org/licenses/by/4.0/

\begin{abstract}
"On April 20, 1999, the corridors and classrooms of Columbine High School in Littleton, Colorado, reverberated with the sound of gunshots. Two students, armed with assault weapons and explosives, had gone on a rampage, killing a teacher and several of their fellow students. They then turned their guns on themselves." (p. 373) Bullying is epidemic and no longer can be ignored! Within this commentary article, there is a research that has been performed in Norway by Psychologist Dan Olweus that improved the bullying program. One method suggested that a potential key for improvement to the bullying program, if implemented robustly, includes: seeing, thinking, and doing social skills. Another method would consist of having all parties within the public school system be involved and work together to help stop unwanted aggressive behavior. This could involve identifying the problem and educating school staff as well as parents on bullying. Next, develop a program, as Dr. Olweus has described in his approach. Finally, implement the program. Dr. Olweus' results noted a decrease in bullying by half in every grade level. The purpose of this article is to help the school systems either improve any anti-bullying program that is already implemented or help to guide and discuss a successful program if none currently exists. Unfortunately, bullying will most likely always exist, just as many kinds of discrimination exist. However, there may be other benefits for children who learn social skills positively. For example, having deeper levels of empathy, learning to have a communal relationship versus exchange relationship, or being a more romantic partner. Moreover, if bullying decreases within the public school system, then children may miss less school and obtain a quality education.
\end{abstract}

\section{Keywords}

Bullying, Empathy, Olweus, Schools

\section{Introduction}

Before a plane takes off, there are always safety instructions and demonstrations 
that are required by airlines to scrutinize before takeoff. One of the safety instructions demonstrates the use of the oxygen mask. Notably, part of the oxygen mask safety instructions states, "Secure your own mask first, before assisting the other person." (Airodyssey.net, 2017) This particular instruction is interesting because it challenges us to perform a series of behaviors that will actually help those around us but not in a manner that is intuitive. In particular, we may want to put on someone else's mask first in order to help them, a relatively noble thing to do. However, if we are unable to function due to not having oxygen of our own, we not only fail them by getting in their way, but fail ourselves as well. This particular scenario is brought up as it portrays a series of actions that fulfill the greater need of everyone around us and does so in a way that we may not currently be thinking about. Below, I discuss some ideas, proposed and tested, that came up with ways to deal with bullying in schools. Notably, these ideas proposed that we do our best to see those things around us, to think about the situation at hand and finally, to do something about it. The last point, doing something about it, was novel in that it employed a massive education campaign with minor reprimands, something we may not think about when dealing with bullies. Overall, this work paves a way for us to think about how to curb bullying in the school system by engaging all parties involved and instilling a sense of empathy in all parties as well, which may have other long lasting benefits.

\section{The Challenge of Bullying}

Bullying is one of the many challenges that school systems face in modern times. For instance, a mother speaks out on the behalf of her 6 year old daughter, Rachel and how bullying impacted her in school. "Now, my daughter, at the age of 6 , is severely depressed, has self-esteem issues, anxiety, been diagnosed with PTSD, has gotten to the point of self-harm and suicidal thoughts, and is in weekly therapy." (Tyler Clementi Foundation, 2016) Another example is a description of Emilie Olsen's parents speaking out on the behalf of their daughter and how bullying impacted Emilie. "It started in the fifth grade, according to the complaint, when Emilie took to wearing camouflage-patterned clothing and cowboy boots. Her style allegedly prompted jeers from classmates, who called her 'fake country' because 'Chinese people don't wear camo'. The bullying only intensified in seventh grade, the complaint said, when Emilie was placed in the same learning group as several girls who had allegedly harassed her the year before. By then, Emilie had started to inflict self-harm and express suicidal and depressive thoughts. On Dec. 11, 2014, the 13-year-old shot and killed herself at home." (Washington Post, 2016) According to Dictionary.com, "Bullying is a blustering, quarrelsome, overbearing person who habitually badgers and intimidates smaller or weaker people." (Dictionary.com, 2017) Bullying is widespread and can impact a victim to the point of suicide. It is also an aggressive, unwanted behavior that can be omitted by our society when specific social skills are learned in a positive manner. A current definition of a Social skill is "any skill facilitating 
interaction and communication with others" (Wikipedia, 2017). Social rules and relations are created, communicated, and changed in verbal and nonverbal ways. "Dr. Eileen Kennedy-Moore suggests that there are crucial aspects needed for the social skills needed to curb bullying, including seeing, thinking and doing" (Psychology Today, 2011).

\section{Strategies to Deal with Bullying}

In brief, seeing involves watching or observing other people's behavior, thinking is interpreting other people's behavior, and doing involves socially interacting with others in a positive way. Interestingly, these descriptions describe the core tenets of "empathy". In addition, if a child can understand how another person feels, then they can share and express their feelings of the other person regardless of what they have to gain. According to C. Daniel Batson, "Empathy is the ability to put oneself in the shoes of another person and to experience events and emotions the way that person experiences them." (Aronson et al., 2007: 348) Furthermore, "Children who are taught to put themselves in others' shoes often have high self-esteem, are more generous, and are less aggressive than children who lack empathy skills." (Aronson et al., 2007: 407) Another example is Batson's empathy-altruism hypothesis which states, "When we feel empathy for another person, we will attempt to help the person for purely altruistic reasons regardless of what we have to gain." (Aronson et al., 2007: 348)

Dr. Dan Olweus was one of the first scientists to assess the problem of bullying in schools and wrote a ground breaking book on the topic Aggression in the School (Olweus, 1980). He went on to implement an intervention to curb bullying in Norway. To this end, he implemented a combination of education as well as mild punishment. Dan Olweus' intervention included: meetings with parents and school staff, cooperative learning groups within a classroom setting, and finer counseling accessible to bullies and their parents. Dan Olweus intervention states, "First, communitywide meetings were held to explain the problem. Parents were given brochures detailing symptoms of victimization. Teachers received training on handling bullying. Students watched video tapes to evoke sympathy for victims of bullying. Second, classes discussed ways to prevent bullying and befriend lonely children. Teachers organized cooperative learning groups and moved quickly to stop name-calling and other aggression that escalates into bullying. Principals ensured that lunchrooms, bathrooms, and playgrounds were adequately supervised. A third set of measures came into play if bullying occurred despite these preventive steps. Counselors intervened using a combination of mild punishment and intensive therapy with the bully and counseling with the bully's parents." For example, with Olweus' approach combined with the key elements for undoing bullying, "seeing would involve observing other's behavior or watching videos, thinking would include class discussions or problem solving/critical thinking, doing is counseling, handing out brochures, and mild punishment." 
Twenty months after the campaign began, Dr. Olweus found that bullying overall had decreased by half, with improvements at every grade level (Olweus, 1980). In addition, if school staff teach children how to diffuse aggression by apology, communication and problem solving, or empathy, then aggressive behavior can decrease before escalating. With this being said, I hypothesize that school systems can successfully implement and tailor social skills with critical thinking and problem solving to elementary, middle, and high schools. Using Dr. Olweus' approach, other groups have reported success in curbing bullying in schools (Bowllan 2011; Schroeder et al., 2012; Nocentini \& Menesini 2016). In addition, implementing a bullying program that is more robust with respect to the approaches performed by the Olweus group that include finer counseling, educating parents on victimization with brochures, and education of the school staff on how to handle aggressive behavior before it escalates. Even though funding may be an obstacle, it is possible that the school staff, such as teachers and counselors, be required to take mandatory training dealing with the key social skills described above. In addition, they would have refresher education through continuing education credits.

\section{Conclusion}

In conclusion, the research that has been performed by Dr. Olweus suggests that bullying may decrease in the public school system implemented robustly. Although a bullying program is a process that needs to be executed and if not, then the implantation is useless. Furthermore, not only can bullying decrease but also can absences. For instance, the statistics gathered for absences due to impact of bullying estimate about 160,000 children miss school each day because of the fear of bullying (National Voices for Equality, Education, and Enlightenment, 2016). Additionally, it is estimated that there are about " 2.1 million bullies and 2.7 million of their victims" (National Voices for Equality, Education, and Enlightenment, 2016). Needless to say, if thousands of school-aged students are missing school every day because they feel unsafe, then how are they getting a quality education? "Teacher effectiveness is the strongest school-related determinant of student success, but chronic student absence reduces even the best teacher's ability to provide learning opportunities." (National Center for Education Statistics, 2009) "Consequently, absences can impact the quality of education, but also later outcomes. For example, Poor attendance has serious implications for later outcomes as well." (National Center for Education Statistics, 2009) Also longitudinal results reveal, "High school dropouts have been found to exhibit a history of negative behaviors, including high levels of absenteeism throughout their childhood, at higher rates than high school graduates. These differences in absentee rates were observed as early as kindergarten, and students who eventually dropped out of high school missed significantly more days of school in first grade than their peers who graduated from high school. In eighth grade, this pattern was even more apparent and, by ninth grade, atten- 
dance was shown to be a key indicator significantly correlated with high school graduation." (National Center for Education Statistics, 2009) "Furthermore, if bullying decreases from positively taught social skills, it is potential that children can govern qualities of a communal relationship versus an exchange relationship." According to Margaret Clark and Judson Mills, "Communal relationships are governed by not being repaid immediately, do not feel exploited when our favors are not repaid, do not keep track of who is contributing to the relationship, and helping other people put us in a good mood. Whereas, exchange relationships are governed by being repaid immediately for our favors, feel exploited when our favors are not returned, keep track of who is contributing what to the relationship, and helping other people has no effect on our mood." (Aronson et al., 2007: 335) In addition, children who learn social skills positively, may acquire other life skills that include caring qualities that may make a more romantic partner or acquiring deeper levels of empathy for others that may aid individuals at their work and in family life, and potentially pass these skills on to the next generation. Dr. Elliott D. Cohen presented a view of love with caring activities. The article stated, "A set of caring activities including being loyal, consistent, candid, trustworthy, considerate, empathetic, tolerant, beneficent, and being there." (Psychology Today, 2013) Social skills correspond with the caring activities that Dr. Cohen states.

The limitations did not examine if bullying is caused by other compounds such as: appearance, race, ethnicity, or social economic. Additionally, bullying was examined within a controlled variable, the school system and not a non-controlled variable, outside of school system. Suggestions for future research can include creating mandatory anti-bullying program(s) for school staff to take. Also, to examine the causes of bullying or aggressive behavior outside of a non-controlled variable.

\section{Acknowledgements}

JBM would like to thank Daniel L Vogt, PhD.(UCSF) and Gilbert Singletary, $\mathrm{PhD}$. (Chamberlain University) for their support and discussion regarding this paper.

\section{References}

Airodyssey.net (2017). Inflight Passenger Announcements. https://airodyssey.net/reference/inflight/

Aronson, E., Wilson, T. D., \& Akert, R. M. (2007). Social Psychology (6th ed., pp. 335, 348-349, 373, 398, 407). Upper Saddle River, NJ: Pearson.

Bowllan, N. M. (2011). Implementation and Evaluation of a Comprehensive, School-Wide Bullying Prevention Program in an Urban/Suburban Middle School. Journal of School Health, 81, 167-173.

Dictionary.com (2017). http://www.dictionary.com/browse/bullying?s=t

National Center for Education Statistics (2009). Every School Day Counts: The Forum Guide to Collecting and Using Attendance Data. 
https://nces.ed.gov/pubs2009/attendancedata/chapter1a.asp

National Voices for Equality, Education, and Enlightenment (2016). Statistics. http://www.nveee.org/statistics/

Nocentini, A., \& Menesini, E. (2016). KiVa Anti-Bullying Program in Italy: Evidence of Effectiveness in a Randomized Control Trial. Prevention Science, 17, 1012-1023. https://doi.org/10.1007/s11121-016-0690-Z

Olweus, D. (1980). Aggression in the School: Bullies and Whipping Boys. Washington D.C.: Hemisphere, 4-218.

Psychology Today (2011). What Are Social Skills? Growing Friendships. https://www.psychologytoday.com/blog/growing-friendships/201108/what-are-social-s kills

Psychology Today (2013). What Would Aristotle Do? Is There Love at First Sight? https://www.psychologytoday.com/blog/what-would-aristotle-do/201307/is-there-lovefirst-sight

Schroeder, B. A., Messina, A., Schroeder, D., Good, K., Barto, S., Saylor, J., \& Masiello, M. (2012). The Implementation of a Statewide Bullying Prevention Program: Preliminary Findings from the Field and the Importance of Coalitions. Health Promotion Practice, 13, 489-495. https://doi.org/10.1177/1524839910386887

Tyler Clementi Foundation (2016). Stories about Bullying. https://tylerclementi.org/rachels-story-charleston-sc/

Washington Post (2016). After Years of Alleged Bullying, an Ohio Teen Killed Herself. Is Her School District Responsible?

https://www.washingtonpost.com/news/morning-mix/wp/2016/05/23/after-years-of-all eged-bullying-an-ohio-teen-killed-herself-is-her-school-district-responsible/?utm_ter $\underline{\mathrm{m}=.8 \mathrm{ed} 84 \text { caaeb6d }}$

Wikipedia (2017). Social Skills. https://en.wikipedia.org/wiki/Social_skills 